\title{
Early rising children are more active than late risers
}

\section{Jun Kohyama}

Department of Pediatrics, Tokyo Kita Shakai Hoken Hospital, Tokyo, Japan
Correspondence: Jun Kohyama

Department of Pediatrics, Tokyo

Kita Shakai Hoken Hospital, 4-17-56

Akabanedai, Tokyo II5-0053, Japan

$\mathrm{Tel}+81359633311$

Fax +8I 359636678

Email j-kohyama@tokyokita-jadecom.jp
Background: A low level of physical activity impacts mental as well as physical health. This study investigated the daily lifestyle habits that affect physical activity in young children.

Methods: The relationship between physical activity, assessed by means of a Mini-Mitter Actiwatch device, and observed daily lifestyle habits was analyzed for 204 children, aged 12 to 40 months (average: 22.6 months), for whom 6-consecutive-day data from both the Actiwatch and sleep $\log$ were obtained.

Results: An older age, male gender, and early waking time showed significant positive correlations with physical activity level. Multiple regression analysis revealed that these three variables were significant predictors of physical activity.

Conclusion: Promoting an early rising time is suggested to be an important element of cultivating good health in young children.

Keywords: physical activity, children, actigraphy, morning light

A British cohort study of more than 30 years' duration (Viner and Hotopf 2004) has shown that sedentary behavior during childhood also increases the risk of chronic fatigue syndrome/myalgic encephalomyelitis. In contrast, physical activity (PA) decreases the risk of obesity, which is an important risk factor for cardiovascular and metabolic disorders (Haslam and James 2005). Moreover, PA is reported to enhance brain health in general (Cotman and Berchtold 2002). Exercise-derived benefits to brain function have been demonstrated at the molecular level (Berchtold et al 2005), and PA has been reported to decrease the risk for Alzheimer's disease (Friedland et al 2001; Rovio et al 2005). PA is one of the key behavioral activities for promoting healthy brain function in animals, including humans. Thus, identification of the behavioral factors in childhood that increase the performance of PA is important for the promotion of both mental and physical health.

In 1979, 8.1\% of children attending day nurseries in Japan were reported as yawning frequently in the morning, and $10.5 \%$ as becoming easily tired (Abe 2005). In 2000, these numbers increased remarkably, to $53.2 \%$ and $76.6 \%$, respectively (Abe 2005). In accordance with these changes, the reported disturbance of basic daily life habits has progressively been increasing in young children in Japan; the rate of 3-year-old children who went to bed later than $10: 00$ pm was $22 \%$ in 1980 , and $52 \%$ in 2000 (Kawai 2001). I also reported that the rate of late sleepers whose sleep onset time was 10:00 pm or later was 43.0\% among 307 18-month-old infants living in Tokyo, and 53.7\% among 151 36-month-old infants living in Tokyo, respectively (Kohyama et al 2000). Moreover, I found $49.6 \%$ of 3-year-old children living in a suburb of Tokyo fell asleep at 10:00 pm or later (Kohyama et al 2002). Based on these figures, I hypothesized that the number of inactive children is increasing in Japan, and that the habits of basic daily life influence the activity level of these children. The present 
study was a preparatory one, aiming to establish the effects of daily life habits on PA in young children.

\section{Methods}

Between July 2002 and November 2006, 285 children aged 6-49 months were studied after obtaining written informed consent from their guardians. All of the children were recruited through the Chuo Honcho Public Health Center in the Adachi District of Tokyo, Japan.

Daily PA was assessed using the Mini-Mitter Actiwatch (model AWLP-AM) $($ AW), a small device $(37 \times 29 \times 11 \mathrm{~mm})$ consisting of an omnidirectional accelerometer sensitive to 0.01 gravity $\left(0.098 \mathrm{~m} / \mathrm{s}^{2}\right)$. The information on acceleration is altered into an electrical current that varies in magnitude, and is then stored as activity counts (Minimitter Company Incorporated 1999). The maximum sampling frequency is $32 \mathrm{~Hz}$ (Minimitter Company Incorporated 1999; LopezAlarcon et al 2004). The daily average activity counts per minute from waking in the morning until falling asleep in the evening [PA (counts/min/day)] were assessed.

According to previous studies (Nishihara et al 2002; Lopez-Alarcon et al 2004; Sulemana et al 2006), the AW device was placed on the ankle of each child for 7 consecutive days, during which period the guardians recorded sleep logs for the children. Times when the AW was removed were also recorded. They were also asked to describe the child's behavior in as much detail as possible during this period. No other special instruction was made for guardians and their children, and they were asked to live their ordinary daily lives. Activity counts and time duration in minutes during the period when the AW was removed (eg, during bathing) as well as the period when nap was taken were omitted from the calculated PA. Times of sleep onset and waking, including napping, were confirmed by matching the records in the sleep logs based on the observation of guardians with the AW data (Benson et al 2004). Since guardians were asked to record the time when their child fell asleep but not the time when the children went to bed, sleep latency could not be measured in the present study.

PA, nap duration on the day when PA was calculated, waking time on the morning of the day, sleep duration of the previous night, and sleep onset time of the previous night were examined. The average values for these measures were calculated for each child, and these average values were used for calculating correlation coefficients. The fluctuation bands for sleep onset and waking times were calculated using the difference between the earliest and latest bedtimes within the recorded period. Correlation coefficients between PA and gender (male: 1, female: 2), age in months, sleep onset time of the previous night, sleep duration of the previous night, waking time in the morning, nap duration during the day, and the bands for sleep onset and waking times were assessed. Correlation coefficients of age in months with sleep onset time of the previous day, sleep duration of the previous night, waking time in the morning, and nap duration during the day were also calculated. Multiple linear regression analysis was used with PA as a dependent variable. The corresponding set of independent variables included age in months, gender, and daily life habits. $\mathrm{p}<0.05$ was considered statistically significant.

\section{Results}

A complete 7-day data set from both the AW and sleep $\log$ were obtained for only 22 children. Fifty-nine children yielded data for $<5$ days. Consequently, 6 -consecutive-day data from both the AW and sleep log were obtained from 204 children (103 male and 101 female). The data obtained from these 204 children were used for analysis. Their ages ranged from 12 to 40 months (mean $22.6 \pm 7.3$ months).

In the sleep logs, most guardians described behaviors of their children in detail. According to these records, I judged that these children lived their ordinary daily lives even during the study period with AW on their ankle.

The average sleep onset time was 21:24 (range: 19:0324:08, standard deviation [SD]: 49.2 minutes) (Table 1). In 42 children (20.6\%), the average sleep onset time was 22:00 or later. The average night sleep duration was 9.9 hours (range: 7.8-14.0, SD: 0.8), waking time was 7:19 (range: 5:05-10:29, SD: 49.8 minutes), nap duration was 1.7 hours (range: $0-3.3$, SD: 0.6), the fluctuation band for the sleep onset time was 1.7 hours (range: $0-6.5, \mathrm{SD}: 1.2$ ) and that for the waking time was 1.5 hours (range: 0.2-7.0, SD: 0.9), respectively (Table 1 ).

Among the correlation coefficients calculated (Table 2), significant positive correlations were obtained between older age and PA, as well as sleep onset time and waking time. Significant negative correlations were obtained between waking

Table I Average values for daily life habits

\begin{tabular}{lll}
\hline & Mean value (range) & SD \\
\hline Sleep onset time (clock time) & $21: 24(19: 03-24: 08)$ & $49.2 \mathrm{~min}$ \\
Night sleep duration (h) & $9.9(7.8-14.0)$ & 0.8 \\
Waking time (clock time) & $7: 19(5: 05-10: 29)$ & $49.8 \mathrm{~min}$ \\
Nap duration (h) & $1.7(0-3.3)$ & 0.6 \\
Band for sleep onset time (h) & $1.7(0-6.5)$ & 1.2 \\
Band for waking time (h) & $1.5(0.2-7.0)$ & 0.9 \\
\hline
\end{tabular}


Table 2 Correlation coefficients for the obtained data

\begin{tabular}{|c|c|c|c|c|c|c|c|c|}
\hline$(n=204)$ & $\begin{array}{l}\text { gender } \\
\text { (male:I, } \\
\text { female: } 2 \text { ) }\end{array}$ & $\begin{array}{l}\text { Age in } \\
\text { months }\end{array}$ & $\begin{array}{l}\text { Sleep } \\
\text { onset } \\
\text { time }\end{array}$ & $\begin{array}{l}\text { Sleep } \\
\text { duration } \\
\text { of the night }\end{array}$ & $\begin{array}{l}\text { Waking } \\
\text { time of } \\
\text { the day }\end{array}$ & $\begin{array}{l}\text { Nap } \\
\text { duration } \\
\text { of the day }\end{array}$ & $\begin{array}{l}\text { Band for } \\
\text { sleep } \\
\text { onset time }\end{array}$ & $\begin{array}{l}\text { Band for } \\
\text { waking } \\
\text { time }\end{array}$ \\
\hline PA & $-0.21 * *$ & $0.14 *$ & -0.07 & -0.11 & $-0.17^{*}$ & -0.07 & -0.01 & -0.09 \\
\hline Age in months & $\mathrm{nc}$ & $\mathrm{nc}$ & $0.17^{*}$ & 0.05 & $0.21 * *$ & $-0.29 * *$ & 0.10 & -0.03 \\
\hline
\end{tabular}

Notes: ${ }^{*} \mathrm{p}<0.05 ;{ }^{*} \mathrm{p}<0.01$; nc: not calculated.

time and PA, and between age and nap duration. According to the correlation coefficient between PA and gender, males were found to increase PA significantly. PA also increased significantly with an older age and early waking time. Using 7:30 am as a cut-off time, and comparing PA, the average PA of children who woke up earlier than 7:30 (442.1, SD: $95.7, \mathrm{n}=124$ ) was significantly higher than that of children who woke up at 7:30 am or later (402.9, SD: $96.9, \mathrm{n}=80)$ $(\mathrm{p}<0.005)$.

Based on multiple linear regression analysis, a significantly predictable regression formula was obtained for PA. Significant regression coefficients with respect to PA was obtained for gender $(p=0.006)$, waking time $(p=0.008)$, and months of age $(\mathrm{p}=0.010)$.

\section{Discussion}

In this study, daily PA was assessed by means of AW, which has been reported as a valid and useful device for the assessment of PA in children (Puyau et al 2002). In adults, AW is worn on the wrist, but it is also worn on the belt or on the ankle in children and adolescents. Although it is hard to say that ankle activity is fully correlated with overall systematic muscular activity, several papers reported that PA measured by AW on the ankle could be an indicator of PA in infants (Nishihara et al 2002), children (Lopez-Alarcon et al 2004), and in adolescents (Sulemana et al 2006). According to these reports, I placed AW on the ankle, though its adequacy needs to be discussed. None of the children included in this study were too young to walk.

This study determined times of sleep onset and waking including napping by matching the records in the sleep logs with the AW data. Acebo and colleagues (2005) reported the overall similarities between actigraph sleep measures and mother-reported measures, although actigraph-based nocturnal wake minutes were higher than maternal diary reports. Since the present study neglected nocturnal waking, an adequacy of determined data was considered as proper.

This study reveals PA to be significantly correlated with older age and male gender. These results are consistent with our experience that the activity of a child increases with age, and that male children are generally more active than female children. In addition, the present study shows a significant negative correlation between age and nap duration. This finding is also in accord with previous reports (Weissbluth 1995).

In this study, nocturnal sleep and nap duration did not exhibit a significant correlation with PA. If one presumes that adequate rest is indispensable for increasing PA, then children who sleep properly might have better PA. However, our findings did not support this assumption. The required sleep duration for an individual is very difficult to determine because the need for sleep is variable (Carskadon and Dement 2005). One explanation may be that individual requirements for sleep vary, and thus there is no single specific sleep amount that is predictive of PA.

In the preliminary study (Yokomaku and Kohyama 2006), children who had smaller bands for sleep onset and waking times showed lower (= better) scores for some subscales of child behavior check list than those who had larger bands, and the distribution of clinical classification were significantly better for children with smaller band for sleep onset than those who had a larger one. However, in the current study, fluctuation bands for sleep onset and waking times did not affect PA. Effects of regularity of daily life habits on the child's health remain to be discussed.

The current study does, however, show PA to be significantly correlated with earlier waking time, and late risers were found to be more inactive than early risers. PA has so far been discussed as a key behavioral activity for promoting healthy brain function. However, patients with attentiondeficit/hyperactivity disorder are known to be pathologically overactive (Simms 2004). In addition, these patients are also widely reported to be poor sleepers (O’Brien et al 2003), and sleep disorders including obstructive sleep apnea syndrome frequently result in behavioral symptoms such as hyperactivity (Simms 2004). Early risers who are sleep-deprived could exhibit pathological daytime over-activity, resulting in the increase of PA. It is hard to rule out this possibility, since 
the present device for calculating PA does not discriminate between normal and pathological activity. However, with the increasing numbers of children who go to bed late at night and wake up late in the morning (Kawai 2001), there is considerable concern among nursery staffs that the number of children who are exhausted or inactive is increasing (Suzuki et al 2002). A currently obtained result that late risers were more inactive than early risers might be a clue to help these inactive children. But why were late risers more inactive than early risers? One possible explanation could be the involvement of morning light.

Morning light is known to be a powerful cue for shortening the circadian cycle of the biological clock, which is naturally longer than $24 \mathrm{~h}$ in most humans (Wever 1979). Consequently, morning light synchronizes the circadian cycle of the biological clock with the $24 \mathrm{~h}$ cycle of the earth (Minors et al 1991). Without this time cue, our daily rhythms are apt to act abnormally causing tiredness, impaired alertness and performance, disorientation, gastrointestinal problems, loss of appetite, and inappropriate timing of defecation (Arendt et al 2005). In addition, light exposure in the morning has been reported to be effective for patients with depression (Goel et al 2003; Baghai et al 2006; Jorm et al 2006) and seasonal affective disorder (Terman et al 1989; Terman and Terman 2005; Michalak et al 2007). Lack of exposure to morning light must produce an unfavorable condition for these patients, and might also be so for young late risers in Japan.

However, the current study did not measure the duration and intensity of light exposure for each child. This is a central issue which remains to be determined to test the current hypothesis on the role of morning light. This pilot study has another weakness, which is that no socio-economic or socio-educational data on the families were obtained. These factors could affect both basic daily life habits and PA, and should be assessed in future studies.

The average sleep onset and waking times obtained in the current study, 21:24 and 7:19, respectively, are earlier than those in the previous study from 2002: 21:44 and 7:48, respectively (Kohyama et al 2002). In addition, the rate of children who fell asleep at 22:00 or later was reduced in the current study than in our former studies (Kohyama et al 2000; 2002). A recent nationwide social promotion program to encourage children waking up early in the morning and going to bed early in the night, supported by the Ministry of Education, Culture, Sports, Science and Technology, might have contributed to this differing result. However, the current study also showed a positive significant correlation between age and both sleep onset and waking times. The social promotion of the favorable daily life habits on physical and mental health should be continued.

\section{Acknowledgments}

I thank the staff of Chuo Honcho Public Health Center in the Adachi District of Tokyo for their generous cooperation.

\section{References}

Abe S. 2005. Differences in physical status of children (in Japanese). In: Nihon Kodomo Wo Mamorukai ed. Kodomo Hakusho. Tokyo: Soudo Bunka. p 108-10.

Acebo C, Sadeh A, Seifer R, et al. 2005. Sleep/wake patterns derived from activity monitoring and maternal report for healthy 1 - to 5-year-old children. Sleep, 28:1568-77.

Arendt J, Stone B, Skene DJ. 2005. Sleep disruption in jet lag and other circadian rhythm-related disorders. In: Kryger MH, Roth T, Dement WC eds. Principles and practice of sleep medicine 4th ed.: Elsevier Saunders. pp 659-72.

Baghai TC, Moller HJ, Rupprecht R. 2006. Recent progress in pharmacological and non-pharmacological treatment options of major depression. Curr Pharm Des, 12:503-15.

Benson K, Friedman L, Noda A, et al. 2004. The measurement of sleep by actigraphy: Direct comparison of 2 commercially available actigraphs in a nonclinical population. Sleep, 27:986-9.

Berchtold NC, Chinn G, Chou M, et al. 2005. Exercise primes a molecular memory for brain-derived neurotrophic factor protein in the rat hippocampus. Neuroscience, 133:853-61.

Carskadon MA, Dement WC. 2005. Normal human sleep: An overview. In: Kryger MH, Roth T, Dement WC eds. Principles and practice of sleep medicine 4th ed.: Elsevier Saunders. pp 13-23.

Cotman CW, Berchtold NC. 2002. Exercise: A behavioral intervention to enhance brain health and plasticity. Trends Neurosci, 25:295-301.

Friedland RP, Fritsch T, Smyth KA, et al. 2001. Patients with Alzheimer's disease have reduced activities in midlife compared with healthy control-group members. Proc Natl Acad Sci USA, 98:3440-5.

Goel N, Terman JS, Macchi MM, et al. 2003. A placebo-controlled trial of light and negative ion treatment for chronic depression: Preliminary results. Chronobiol Int, 20:1207-9.

Haslam DW, James WP. 2005. Obesity. Lancet, 366:1197-209.

Jorm AF, Allen NB, O'Donnell CP, et al. 2006. Effectiveness of complementary and self-help treatments for depression in children and adolescents. Med J Aust, 185:368-72.

Kawai H. 2001. Investigation on the health of young children in 2000 (in Japanese). J Child Health, 60:543-87.

Kohyama J, Shiiki T, Hasegawa T. 2000. Sleep duration of young children is affected by nocturnal sleep onset time. Pediatr Int, 42:589-91.

Kohyama J, Shiiki T, Ohinata-Sugimoto J, et al. 2002. Potentially harmful sleep habits of 3-year-old children in Japan. J Dev Behav Pediatr, 23:67-70.

Lopez-Alarcon M, Merrifield J, Fields DA, et al. 2004. Ability of the actiwatch accelerometer to predict free-living energy expenditure in young children. Obesity Res, 12:1859-65.

Michalak EE, Murray G, Wilkinson C, et al. 2007. A pilot study of adherence with light treatment for seasonal affective disorder. Psychiatry Res, 149:315-20.

Minimitter Company Incorporated. 1999. Actiwatch 16/Actiwatch 64/ Actiwatch-L Activity Monitors: Instruction Manual. Bend (Oregon, USA): Minimitter Company Corporated.

Minors DS, Waterhouse JM, Wirz-Justice A. 1991. A human phase-response curve to light. Neurosci Lett, 133:36-40.

Nishihara K, Horiuchi S, Eto H, Uchida S. 2002. The development of infants' circadian rest-activity rhythm and mothers' rhythm. Physiol Behav, 77:91-8. 
O’Brien LM, Ivanenko A, Crabtree VM, et al. 2003. Sleep disturbances in children with attention deficit hyperactivity disorder. Pediatr Res, 54:237-43.

Puyau MR, Adolph AL, Vohra FA, et al. 2002. Validation and calibration of physical activity monitors in children. Obesity Res, 10:150-7.

Rovio S, Kareholt I, Helkala EL, et al. 2005. Leisure-time physical activity at midlife and the risk of dementia and Alzheimer's disease. Lancet Neurol, 4:690-1.

Simms MD. 2004. Attention-deficit/hyperactivity disorder. In: Behrman RE, Kliegman RM, Jenson HB eds. Nelson textbook of pediatrics 17 th ed. Saunders. pp 107-10.

Sulemana H, Smolensky MH, Lai D. 2006. Relationship between physical activity and body mass index in adolescents. Med Sci Sports Exerc, 38:1182-6.

Suzuki M, Takahashi C, Nomura Y, et al. 2002. What are care workers concerned about regarding the relationship between young children and their parents? - On inquiring about sleep-wake rhythm of children and their parents' attitude towards raising them (in Japanese). J Child Health, 61:593-8.
Terman M, Terman JS. 2005. Light therapy. In: Kryger MH, Roth T, Dement WC eds. Principles and practice of sleep medicine 4th ed. Elsevier. Saunders. p 1424-42.

Terman M, Terman JS, Quitkin FM, et al. 1989. Bright light therapy for winter depression: A review of efficacy. Neuropsychopharmachology, 2:1-22.

Viner R, Hotopf M. 2004. Childhood predictors of self reported chronic fatigue syndrome/myalgic encephalomyelitis in adults: National birth cohort study. BMJ, 329:941-3.

Wever RA. 1979. The circadian system of man: Results of experiments under temporal isolation. New York: Springer-Verlag.

Weissbluth M. 1995. Naps in children: 6 months-7 years. Sleep, 18:82-7.

Yokomaku A, Kohyama J. Effect of sleeping habits on child behavior. No To Hattatsu, 38:S153. 
